Article

\title{
Ionic Liquid-Based Ultrasonic-Assisted Extraction of Secoisolariciresinol Diglucoside from Flaxseed (Linum usitatissimum L.) with Further Purification by an Aqueous Two-Phase System
}

\author{
Zhi-Jian Tan ${ }^{1, *}$, Chao-Yun Wang ${ }^{1, *}$, Zi-Zhen Yang ${ }^{2}$, Yong-Jian Yi ${ }^{1}$, Hong-Ying Wang ${ }^{1}$, \\ Wan-Lai Zhou ${ }^{1}$ and Fen-Fang $\mathrm{Li}^{2}$
}

1 Institute of Bast Fiber Crops, Chinese Academy of Agricultural Sciences, Changsha 410205, China; E-Mails: ibfcyyj@163.com (Y.-J.Y.); Cswhy328@126.com (H.-Y.W.); aruofly@126.com (W.-L.Z.)

2 College of Chemistry and Chemical Engineering, Central South University, Changsha 410083, China; E-Mails: yzz8582352@163.com (Z.-Z.Y.); 1fflqq@csu.edu.cn (F.-F.L.)

* Authors to whom correspondence should be addressed;

E-Mails: tanzhijiantgzy2010@aliyun.com (Z.-J.T.); ibfcwcy@139.com (C.-Y.W.);

Tel.: +86-731-8899-8517 (Z.-J.T.); Fax: +86-731-8899-8501 (C.-Y.W.).

Academic Editor: Marcello Iriti

Received: 6 July 2015 / Accepted: 10 September 2015 / Published: 30 September 2015

\begin{abstract}
In this work, a two-step extraction methodology of ionic liquid-based ultrasonic-assisted extraction (IL-UAE) and ionic liquid-based aqueous two-phase system (IL-ATPS) was developed for the extraction and purification of secoisolariciresinol diglucoside (SDG) from flaxseed. In the IL-UAE step, several kinds of ILs were investigated as the extractants, to identify the IL that affords the optimum extraction yield. The extraction conditions such as IL concentration, ultrasonic irradiation time, and liquid-solid ratio were optimized using response surface methodology (RSM). In the IL-ATPS step, ATPS formed by adding kosmotropic salts to the IL extract was used for further separation and purification of SDG. The most influential parameters (type and concentration of salt, temperature, and $\mathrm{pH})$ were investigated to obtain the optimum extraction efficiency. The maximum extraction efficiency was $93.35 \%$ under the optimal conditions of $45.86 \%(w / w)$ IL and $8.27 \%(w / w)$ $\mathrm{Na}_{2} \mathrm{SO}_{4}$ at $22{ }^{\circ} \mathrm{C}$ and $\mathrm{pH} 11.0$. Thus, the combination of IL-UAE and IL-ATPS makes up a simple and effective methodology for the extraction and purification of SDG. This process is also expected to be highly useful for the extraction and purification of bioactive compounds from other important medicinal plants.
\end{abstract}


Keywords: ionic liquid; ultrasonic-assisted extraction; aqueous two-phase system; secoisolariciresinol diglucoside; purification

\section{Introduction}

Flaxseed is the richest food source of lignans, a plant secondary metabolite, especially secoisolariciresinol diglucoside (SDG), compared to those found in other plants [1-4]. It also contains omega-3 ( $\omega-3 / n-3)$ polyunsaturated fatty acids (specifically $\alpha$-linolenic acid, ALA), short chain polyunsaturated fatty acids (PUFA) [5,6], a high level of dietary fibers, and good quality protein fractions [7]. In recent years, SDG has attracted increasing interest owing to its pharmacological action, including antidiabetic effects [8], antioxidant activities [9], inhibition of cancer cell growth [10], inhibition of human breast tumor growth [11], and its hypocholesterolemic and antiatherosclerotic effects [12].

Ionic liquids (ILs) are molten salts composed entirely of ions that are in the liquid state at or below $100{ }^{\circ} \mathrm{C}$ [13]. Compared with water and conventional organic solvents, they exhibit distinct physical, chemical, and biological properties such as negligible volatility, a wide electrochemical window, high thermal and chemical stability, exceptional solubility, and antimicrobial and analgesic properties [14-16]. As green solvents, ILs have been widely used in the extraction of active ingredients from natural plants, such as isoflavones from radix puerariae [17], luteolin from peanut shells [18], saponins and polyphenols from mate (Ilex paraguariensis) and tea (Camellia sinensis) [19], saponins from sisal (Agave sisalana) and juá (Ziziphus joazeiro) [20], and flavonoids from Chamaecyparis obtusa leaves [21]. Ultrasound-assisted extraction (UAE) is a common auxiliary method used in the extraction field. UAE can break down the plant tissue more easily and accelerate the penetrating of solvent into the plant tissue, reduce processing time and energy and enhance efficiency in mass and energy transfer [22,23]. Ionic liquid-based ultrasonic-assisted extraction (IL-UAE) has been extensively demonstrated in the efficient extraction of active ingredients from natural plants, such as forskolin from Coleus forskohlii roots [24], isoliquiritigenin, liquiritin and glycyrrhizic acid from licorice [25], and alkaloids from Phellodendron amurense Rupr [26].

An ionic liquid aqueous two-phase system (IL-ATPS) was reported for the first time in 2003 by Rogers and coworkers [27]. The advantages of this system include negligible viscosity, formation of very little emulsion, no need of using volatile organic solvent, and gentle biocompatible conditions of use [28-30]. Up to now, IL-ATPS has been successfully used in the extraction and purification of different compounds such as polysaccharides and proteins [31], gallic acid [32], sulfonamides [28], cephalexin [33], and wheat-esterase [34].

In this paper, we report a two-step extraction using IL-UAE and IL-ATPS to extract and purify SDG from flaxseeds. Five kinds of ILs were considered as the IL-UAE extractant. SDG was further enriched and purified using IL-ATPS. The extraction conditions of the IL-UAE (i.e., IL concentration, ultrasonic irradiation time, and liquid-solid ratio) were optimized using the response surface methodology (RSM). The most influential parameters in IL-ATPS (type and concentration of salt, temperature, and $\mathrm{pH}$ ) were also investigated. 


\section{Results and Discussion}

\subsection{Ionic Liquid-Based Ultrasonic-Assisted Extraction (IL-UAE)}

\subsubsection{Selection of IL}

In order to find the optimal extractant, five types of ILs were investigated for the extraction of SDG from flaxseed powder. Although the pure ILs selected for extraction have low viscosity, some studies reported that despite that ILs normally possesses high viscosity, the presence of water reduces it considerably [35,36]. Therefore, the viscosity of pure ILs is less important when the ILs aqueous solutions are used in the solid-liquid extraction. The results in Figure 1 show that the $\mathrm{IL}[\mathrm{C} 4 \mathrm{mim}] \mathrm{N}(\mathrm{CN})_{2}$ led to the optimum extraction yield. The extraction ability might be related to the hydrophobicity of ILs, as the extraction ability of ILs increases with the increase of IL hydrophobicity. The hydrophobicity of the ILs used in this study follow the order: $\left[\mathrm{C}_{2} \mathrm{mim}\right] \mathrm{OTf}<\left[\mathrm{C}_{2} \mathrm{OHmim}\right] \mathrm{N}(\mathrm{CN})_{2}<\left[\mathrm{C}_{4} \mathrm{mim}\right] \mathrm{N}(\mathrm{CN})_{2}<$ $\left[\mathrm{C}_{6} \mathrm{mim}\right] \mathrm{N}(\mathrm{CN})_{2}<\left[\mathrm{C}_{4} \mathrm{mim}\right] \mathrm{OTf}$. However, as to $\left[\mathrm{C}_{4} \mathrm{mim}\right] \mathrm{N}(\mathrm{CN})_{2}$ and [ $\left.\mathrm{C}_{4} \mathrm{mim}\right] \mathrm{OTf}$, because of different solutions have different multi-interactions including $\pi-\pi, \mathrm{n}-\pi$, ionic/charge-charge and hydrogen bonding with SDG of interest, which results in the decrease of extraction yield for [C4mim]OTf [37,38]; as to $\left[\mathrm{C}_{4} \mathrm{mim}\right] \mathrm{N}(\mathrm{CN})_{2}$ and $\left[\mathrm{C}_{6} \mathrm{mim}\right] \mathrm{N}(\mathrm{CN})_{2}$, increasing the alkyl chain length from butyl to hexyl decreases the extraction efficiency, which could be attributed to increased steric hindrance with the longer alkyl chain [39]. Therefore, this IL $\left[\mathrm{C}_{4} \mathrm{mim}\right] \mathrm{N}(\mathrm{CN})_{2}$ has the optimal extraction ability and was chosen as the extractant for further study.

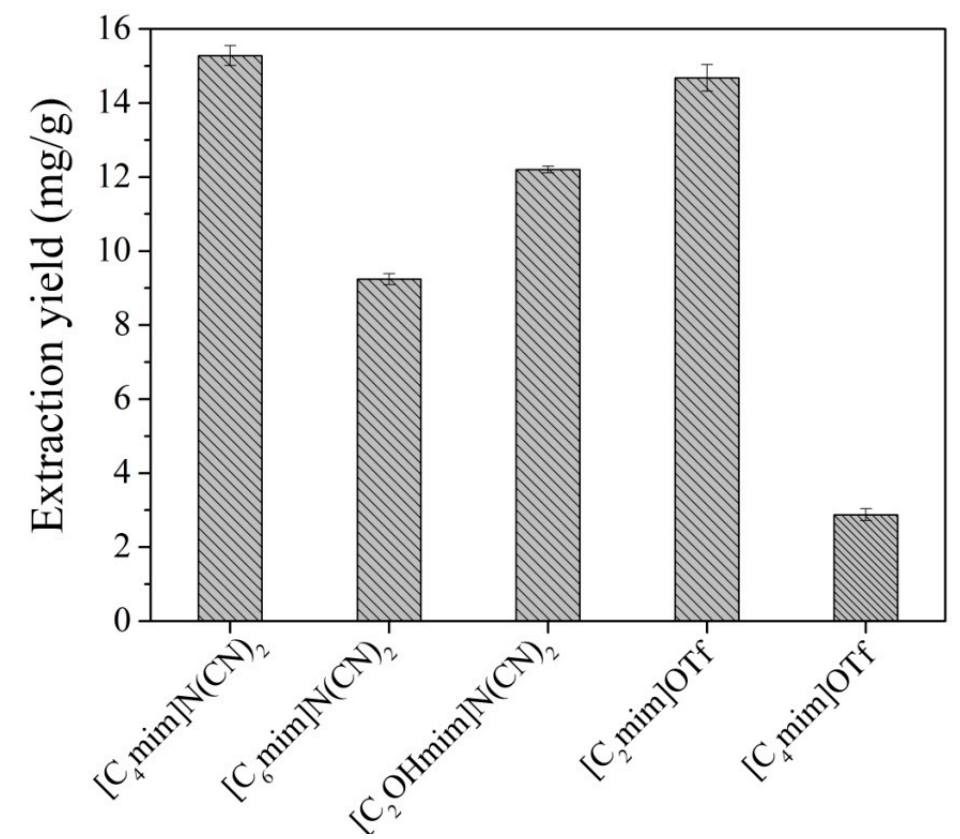

Figure 1. Ionic liquids-based ultrasound-assisted extraction of SDG using five types of ILs.

\subsubsection{Single Factor Experiments}

A number of factors, including IL concentration, liquid-solid ratio, and ultrasonic irradiation time, could affect the UAE extraction yield. Therefore, it is necessary to identify the most influential factors for obtaining the maximum extraction yield. 


\section{Effect of IL Concentration}

The effect of $\left[\mathrm{C}_{4} \mathrm{mim}\right] \mathrm{N}(\mathrm{CN})_{2}$ aqueous solutions with mass concentrations of $20 \%-60 \%(w / w)$ was calculated to determine the optimal concentration of IL-UAE. The liquid-solid ratio and ultrasonic irradiation time were set at constant values of 20:1 and $30 \mathrm{~min}$, respectively. The maximum extraction yield was obtained at IL concentration of $50 \%(w / w)$ (Figure 2). No obvious increase in the extraction yield was observed with further increase in the IL concentration; thus, the IL concentration of 50\% $(w / w)$ was selected for subsequent experiments.

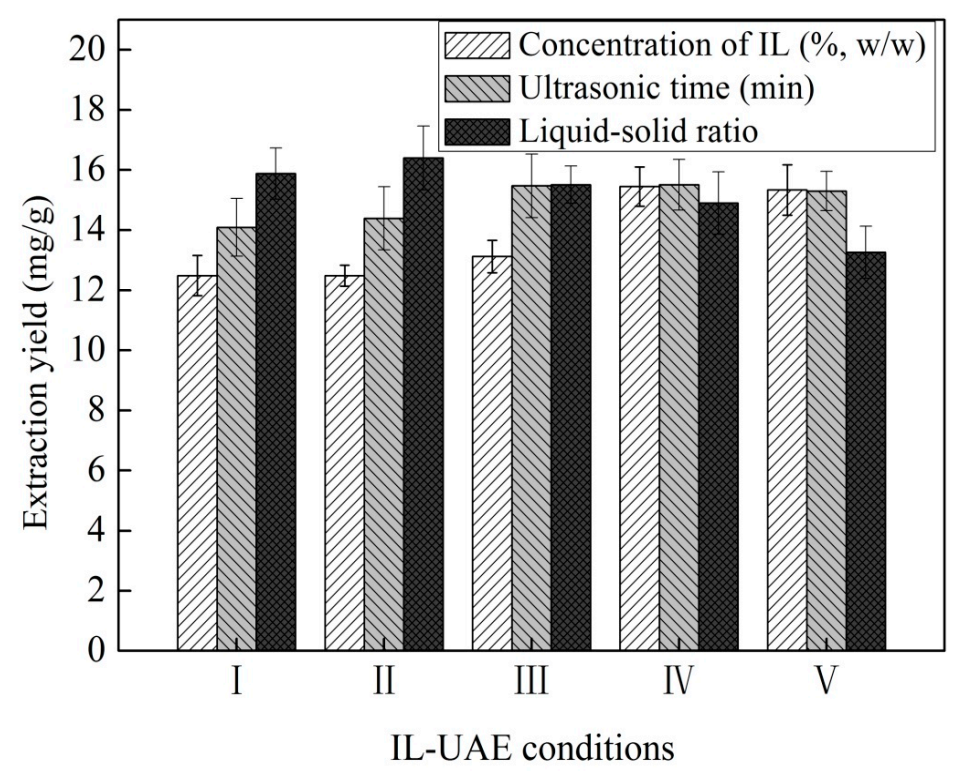

Figure 2. Single-factor experiments of IL concentration (I-V represent the IL concentrations of $20 \%, 30 \%, 40 \%, 50 \%$, and $60 \%(w / w)$ ), ultrasonic irradiation time (I-V represent the ultrasonic irradiation time of $20,30,40,50$, and $60 \mathrm{~min}$ ), and liquid-solid ratio (I-V represent the liquid-solid ratio of 10:1, 20:1, 30:1, 40:1, and 50:1) for the extraction of SDG using IL-UAE.

\section{Effect of Liquid-Solid Ratio}

The liquid-solid ratio is an important parameter influencing the extraction yield. If the liquid-solid ratio is too high, the result would be waste of IL and increased cost, while a too-low ratio would result in incomplete extraction. The effect of liquid-solid ratios of 10:1, 20:1, 30:1, 40:1, and 50:1 was studied to evaluate the influence of this ratio on extraction yield. The IL concentration and ultrasonic irradiation time were set at constant values of 50\% $(w / w)$ and $30 \mathrm{~min}$, respectively. The results in Figure 2 showed that the maximal extraction yield was obtained when the liquid-solid ratio was 20:1.

\section{Effect of Ultrasonic Irradiation Time}

To some extent, the ultrasonic irradiation time also plays an important role in the IL-UAE procedure, because sonication significantly shortens the extraction time. The effect of ultrasonic irradiation time from 20 to $60 \mathrm{~min}$ was studied by maintaining other experimental conditions constant such as IL concentration of $50 \%(w / w)$ and liquid-solid ratio of 20:1. Higher extraction yields were obtained 
when the ultrasonic irradiation time was longer than 40 min; no obvious increase was observed with further increase in time (Figure 2).

\subsubsection{Optimization of IL-UAE Conditions by the Response Surface Method (RSM)}

To further study the interaction between these factors, the conditions were optimized using RSM in Design-Expert 7.0 software (Stat-Ease, Minneapolis, MN, USA). Three factors: IL concentration $(40 \%, 50 \%$, and $60 \%(w / w))$, liquid-solid ratio $(10: 1,20: 1$, and $30: 1)$, and ultrasonic irradiation time (40, 50, and $60 \mathrm{~min})$, were applied using a Box-Behnken design. The experimental conditions are shown in Table 1. Experimental results of the extraction yield of SDG were analyzed by multiple regressions to fit the second-order regression equation. The coded factors of the regression model were predicted to be: $\mathrm{Y}=15.8+0.66 \mathrm{~A}+0.63 \mathrm{~B}+0.12 \mathrm{C}+0.85 \mathrm{AB}-0.21 \mathrm{AC}-0.24 \mathrm{BC}-1.15 \mathrm{~A}^{2}-1.48 \mathrm{~B}^{2}+0.49 \mathrm{C}^{2}$ $\left(\mathrm{R}^{2}=0.9883\right)$, where $\mathrm{Y}$ is the extraction yield in $\mathrm{mg} / \mathrm{g}, \mathrm{A}$ is the $\mathrm{IL}$ concentration $(\%, w / w), \mathrm{B}$ is the liquid-solid ratio, and $\mathrm{C}$ is ultrasonic irradiation time (min).

Table 1. Arrangement and results of the three-factor/three-level response surface design.

\begin{tabular}{ccccc}
\hline Run & $\begin{array}{c}\text { Factor A: IL } \\
\text { Concentration }(\%, \boldsymbol{w} / \boldsymbol{w})\end{array}$ & $\begin{array}{c}\text { Factor B: } \\
\text { Liquid-Solid Ratio }\end{array}$ & $\begin{array}{c}\text { Factor C:Ultrasonic } \\
\text { Irradiation Time (min) }\end{array}$ & $\begin{array}{c}\text { Response Average } \\
\text { Extraction Yield (mg/g) }\end{array}$ \\
\hline 1 & 60 & $10: 1$ & 50 & 12.5521 \\
2 & 50 & $20: 1$ & 50 & 15.7939 \\
3 & 50 & $20: 1$ & 50 & 15.9827 \\
4 & 60 & $30: 1$ & 50 & 15.4370 \\
5 & 50 & $10: 1$ & 40 & 13.7683 \\
6 & 40 & $30: 1$ & 50 & 12.0817 \\
7 & 50 & $30: 1$ & 60 & 15.3657 \\
8 & 50 & $10: 1$ & 60 & 14.5096 \\
9 & 50 & $30: 1$ & 40 & 15.5716 \\
10 & 40 & $10: 1$ & 50 & 12.6094 \\
11 & 60 & $20: 1$ & 60 & 15.5444 \\
12 & 60 & $20: 1$ & 40 & 15.7341 \\
13 & 50 & $20: 1$ & 50 & 15.8536 \\
14 & 50 & $20: 1$ & 50 & 15.7837 \\
15 & 40 & $20: 1$ & 40 & 14.3129 \\
16 & 50 & $20: 1$ & 50 & 15.5716 \\
17 & 40 & $20: 1$ & 60 & 14.9624 \\
\hline
\end{tabular}

It can be seen in Table 2 that the value for the coefficient of determination $\left(\mathrm{R}^{2}\right)$ was 0.9883 , which implies that over $98.83 \%$ of the variation in the process efficiency could be explained by the model. The model F-value of 65.53 and the model $p$-value of $<0.0001$ indicate that the model is significant. There is only less than $0.01 \%$ chance that such a large "Model F-Value" could occur due to noise, implying that the model was acceptable. A "Prob $>$ F" of value less than 0.0500 indicates that the model terms are significant. In this case, $\mathrm{A}, \mathrm{B}, \mathrm{AB}, \mathrm{A}^{2}, \mathrm{~B}^{2}$, and $\mathrm{C}^{2}$ are significant model terms. 
Table 2. Analysis of variance (ANOVA) for the quadratic response surface model.

\begin{tabular}{cccccc}
\hline Source & Degrees of Freedom & Sum of Squares & Mean Square & F-value & $\boldsymbol{p}$-value Prob $>$ F \\
\hline Model & 9 & 26.15 & 2.91 & 65.53 & $<0.0001$ \\
$\mathrm{~A}$ & 1 & 3.51 & 3.51 & 79.23 & $<0.0001$ \\
$\mathrm{~B}$ & 1 & 3.15 & 3.15 & 70.95 & $<0.0001$ \\
$\mathrm{C}$ & 1 & 0.12 & 0.12 & 2.79 & 0.1386 \\
$\mathrm{AB}$ & 1 & 2.91 & 2.91 & 65.66 & $<0.0001$ \\
$\mathrm{AC}$ & 1 & 0.18 & 0.18 & 3.97 & 0.0865 \\
$\mathrm{BC}$ & 1 & 0.22 & 0.22 & 5.06 & 0.0595 \\
$\mathrm{~A}^{2}$ & 1 & 5.53 & 5.53 & 124.76 & $<0.0001$ \\
$\mathrm{~B}^{2}$ & 1 & 9.23 & 9.23 & 208.24 & $<0.0001$ \\
$\mathrm{C}^{2}$ & 1 & 1.00 & 1.00 & 22.57 & 0.0021 \\
Residual & 7 & 0.31 & 0.044 & & \\
Lack of fit & 3 & 0.22 & 0.074 & 3.33 & 0.1376 \\
Pure Error & 4 & 0.089 & 0.022 & & \\
Cor total & 16 & 26.46 & & & \\
\hline
\end{tabular}

The response surfaces for the effects of independent variables on the average extraction yield of SDG are shown in Figure 3. Based on the quadratic model, the optimum conditions for the extraction of SDG were calculated to be IL concentration of $55.49 \%(w / w)$, liquid-solid ratio of $24.50: 1$, and ultrasonic irradiation time of $40 \mathrm{~min}$. Triplicate runs were carried out at the optimum conditions, and the average yield was $16.3374 \mathrm{mg} / \mathrm{g}$, which is very close to the predicted value of $16.5934 \mathrm{mg} / \mathrm{g}$. This demonstrated that the model was adequate for reflecting the expected optimization.

(a)

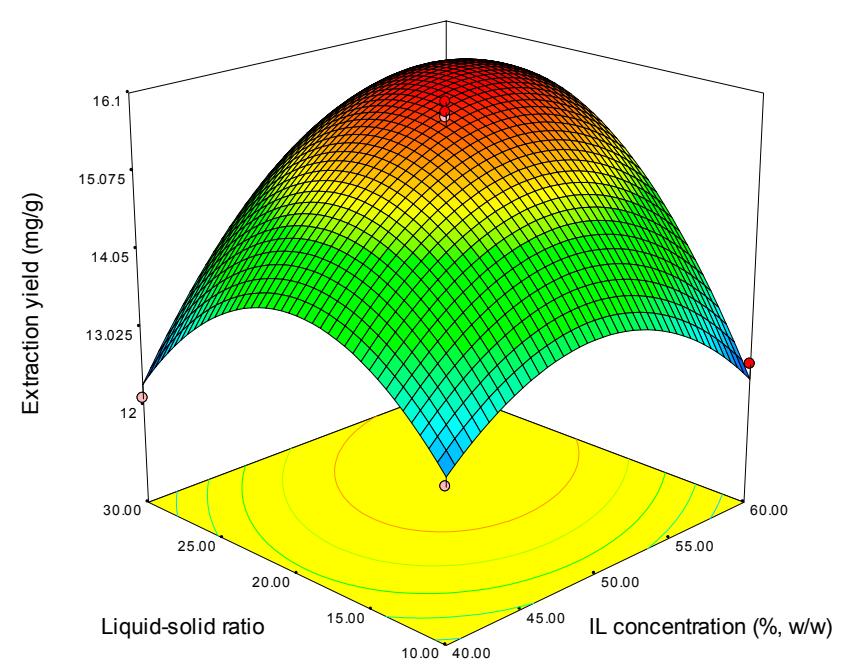

(b)

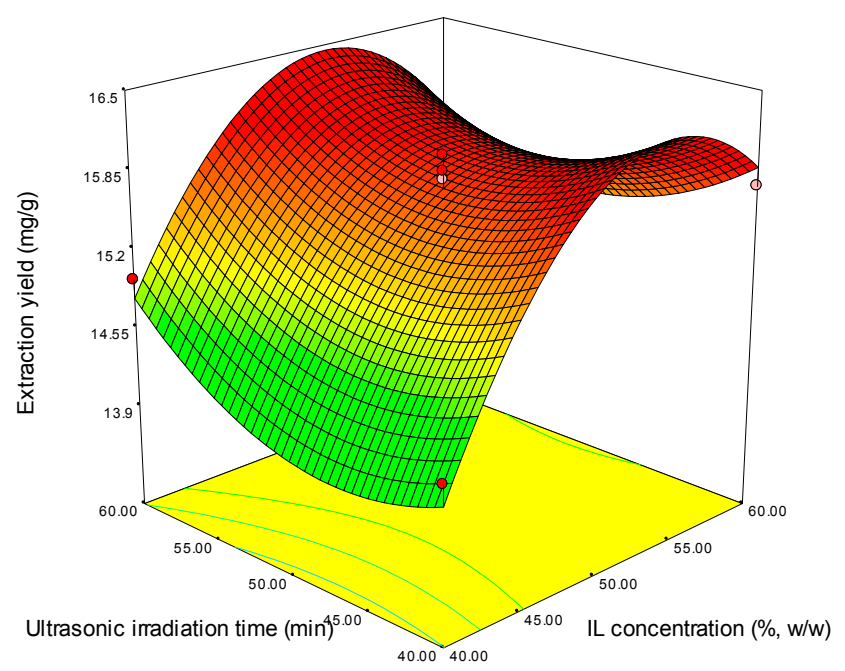

Figure 3. Cont. 
(c)

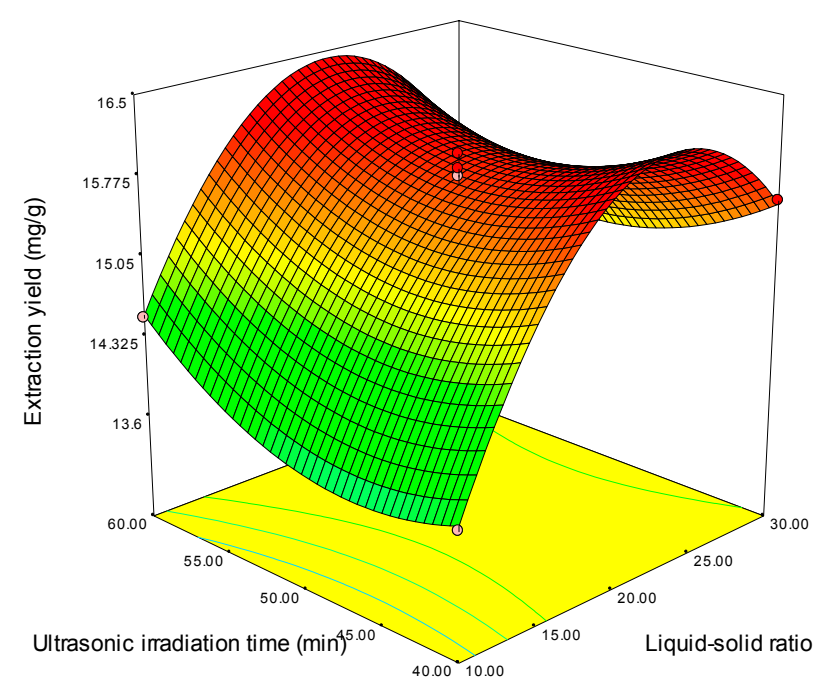

Figure 3. Response surface plots showing the effects of variables on the average extraction yield of SDG: (a) interaction of the IL concentration and liquid-solid ratio; (b) interaction of the IL concentration and ultrasonic irradiation time; and (c) interaction of the liquid-solid ratio and ultrasonic irradiation time.

\subsubsection{Comparison with Other Extraction Methods}

The heat reflux extraction (HRE) and microwave-assisted extraction (MAE) were compared with UAE to extract SDG using $\left[\mathrm{C}_{4} \mathrm{mim}\right] \mathrm{N}(\mathrm{CN})_{2}$ as extractant. The operating temperature of the three methods was set at approximate $40{ }^{\circ} \mathrm{C}$. The results are presented in Table 3, which shows that the IL-UAE and IL-MAE have higher extraction yield and consume a shorter extraction time than IL-HRE. The IL-MAE give similar yield with IL-UAE, however, MAE gives microwave leakage that is potentially harmful to humans compared with UAE.

Table 3. Comparison of three different methods (HRE, MAE, and UAE) for extraction of SDG (IL concentration is $50 \%(w / w)$ and liquid-solid ratio is $20: 1)$.

\begin{tabular}{cccccc}
\hline Extraction Methods & \multicolumn{3}{c}{ HRE } & MAE & UAE \\
\hline Time (min) & 20 & 40 & 60 & 40 & 40 \\
Extraction yield $(\mathrm{mg} / \mathrm{g})$ & 2.6953 & 9.6581 & 12.6324 & 16.1263 & 16.0854 \\
\hline
\end{tabular}

\subsection{Ionic Liquid-Based Aqueous Two-Phase System (IL-ATPS)}

In the IL-ATPS section, a kosmotropic salt was directly added into the IL extract to construct ATPS for further purification of SDG. The influential parameters: type and concentration of salt, temperature, and $\mathrm{pH}$, were investigated.

\subsubsection{Effect of Salt}

Three types of salt, an acid salt [( $\left.\left.\mathrm{NH}_{4}\right)_{2} \mathrm{SO}_{4}\right]$, a basic salt $\left[\mathrm{K}_{2} \mathrm{HPO}_{4}\right]$, and a neutral salt [Na2 $\left.\mathrm{SO}_{4}\right]$, were considered as candidates for the phase-forming salt. It can be seen in Figure $4 \mathrm{a}$ that the ATPSs formed 
by $\mathrm{Na}_{2} \mathrm{SO}_{4}$ had the highest extraction efficiency. The extraction ability of IL-ATPSs follows the phase-forming order of three types of salt: $\mathrm{Na}_{2} \mathrm{SO}_{4}>\left(\mathrm{NH}_{4}\right)_{2} \mathrm{SO}_{4}>\mathrm{K}_{2} \mathrm{HPO}_{4}$. The maximum extraction efficiency was obtained when the ATPS was composed of $45.86 \%(w / w)$ IL and $8.27 \%(w / w) \mathrm{Na}_{2} \mathrm{SO}_{4}$.

(a)

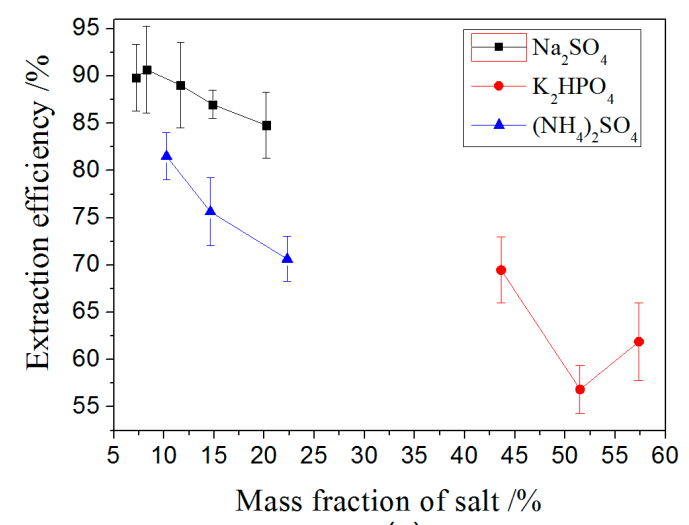

(b)

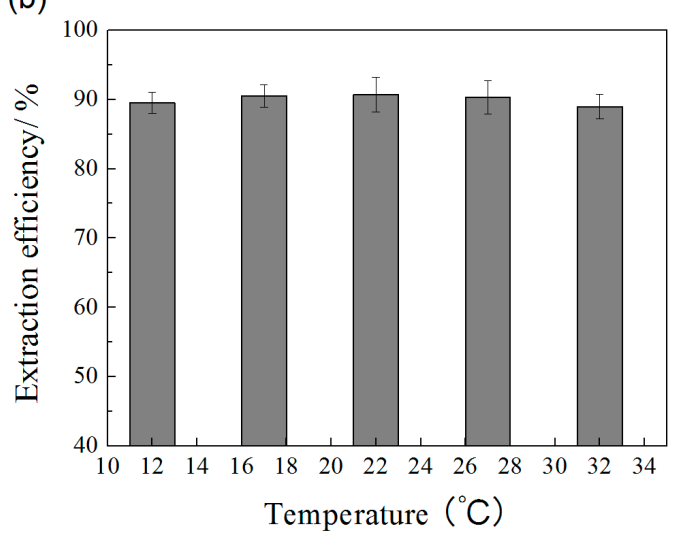

(c)

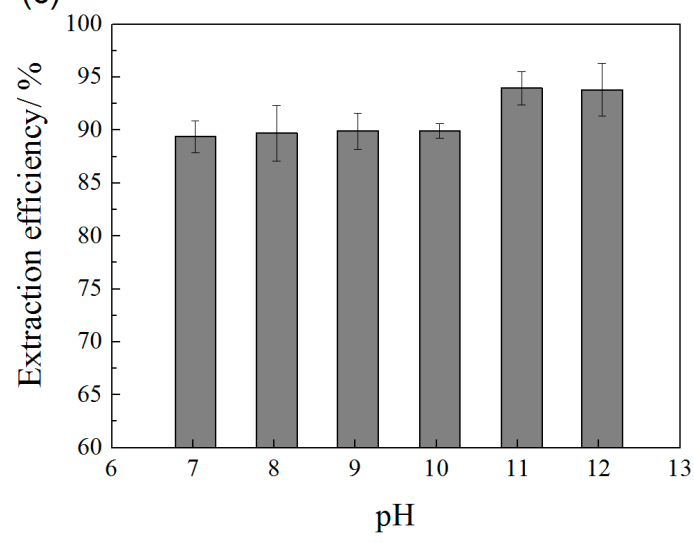

Figure 4. Effect of (a) salt; (b) temperature; and (c) $\mathrm{pH}$ on the extraction efficiency of SDG by IL-ATPS.

\subsubsection{Effect of Temperature}

The partitioning of SDG in IL-ATPS within the temperature range $12-32{ }^{\circ} \mathrm{C}$ was investigated, with unadjusted $\mathrm{pH}$. The results are shown in Figure $4 \mathrm{~b}$. When the temperature was $22{ }^{\circ} \mathrm{C}$, the extraction efficiency was maximum. The higher temperature will be not suitable for the stability for SDG. Moreover, a higher temperature will cause consumption of more energy; therefore, it is better to operate the IL-ATPS closing to the room temperature.

\subsubsection{Effect of $\mathrm{pH}$}

A buffer solution $\left(\mathrm{Na}_{2} \mathrm{HPO}_{4}-\mathrm{H}_{3} \mathrm{PO}_{4}\right)$ was used to adjust the $\mathrm{pH}$ of the ATPS. $\mathrm{Na}_{2} \mathrm{SO}_{4}$ was added into IL-UAE extract to form ATPS. The effect of $\mathrm{pH}$ within the range 7.0-12.0 on the extraction efficiency was investigated. After IL-ATPS, SDG was quantified by HPLC after alkaline hydrolysis of the samples in IL-rich phase. As shown in Figure 4c, it can be observed that the highest extraction efficiency was obtained at $\mathrm{pH} 11.0$. 
To conclude, the maximum IL-ATPS extraction efficiency of $93.35 \%$ was obtained under the following conditions: ATPS 45.86\% $(w / w)\left[\mathrm{C}_{4} \mathrm{mim}\right] \mathrm{N}(\mathrm{CN})_{2}$ and $8.27 \%(w / w) \mathrm{Na}_{2} \mathrm{SO}_{4}$, extraction temperature $22{ }^{\circ} \mathrm{C}$, and $\mathrm{pH}$ 11.0. Under the optimal IL-UAE and IL-ATPS conditions, the HPLC chromatograms for the analysis of SDG samples after IL-UAE and IL-ATPS are shown in Figure 5.

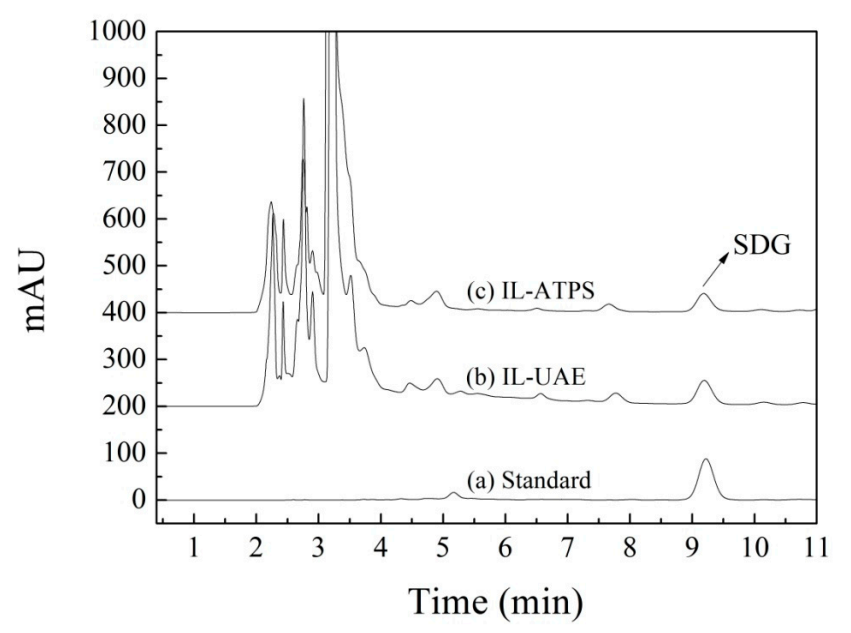

Figure 5. HPLC chromatograms for (a) SDG standard; (b) IL-UAE sample; and (c) IL-ATPS sample.

\subsubsection{SDG Isolation and IL Recycling}

After IL-ATPS, SDG is extracted into IL-rich phase, and how to recovery SDG and IL from the IL-based raw extract is becoming a difficult task. Some literature reported that liquid-liquid back-extraction with organic solvents is a reasonable approach for back-extraction of compounds and recovery of ILs [31,40]. In order to achieve this aim, several non-miscible with water organic solvents of ethyl acetate, $n$-butanol, chloroform, and dichloromethane were tested, to extract SDG into organic phase with IL staying in aqueous phase. SDG can be isolated and IL can be recycled with further treatment after separation of two phases. The results in Figure 6 shows that the maximal back-extraction efficiency of SDG reaches to $98.84 \%$ using $n$-butanol as solvent.

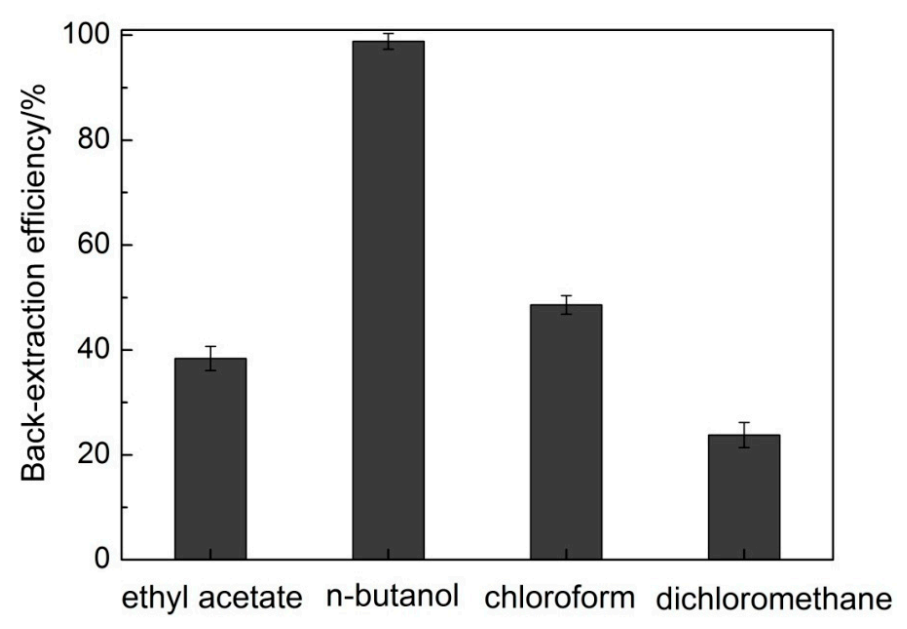

Figure 6. Back-extraction of SDG using organic solvents. 


\section{Experimental Section}

\subsection{Materials and Reagents}

Flaxseeds were harvested and collected in August 2014 from Harbin, Heilongjiang Province, Northeast China. The ILs of $\left[\mathrm{C}_{4} \mathrm{mim}\right] \mathrm{N}(\mathrm{CN})_{2}$ (1-butyl-3-methylimidazoliumte dicyanamide), [C $\mathrm{Cmim}] \mathrm{N}(\mathrm{CN})_{2}$ (1-hexyl-3-methylimidazoliumte dicyanamide), [ $\left.\mathrm{C}_{2} \mathrm{OHmim}\right] \mathrm{N}(\mathrm{CN})_{2}$, (1-(2-hydroxyethyl)3-methylimidazolium dicyanamide), [C2mim]OTf (1-ethyl-3-methylimidazoliumte triflate), and [C4mim]OTf (1-butyl-3-methylimidazoliumte triflate) were synthesized and purified in our laboratory. The viscosity was determined using a Brookfield DV-S viscometer (Middleboro, MA, USA), indicating that the viscosity of all the ILs used in this study was below $50 \mathrm{mPa} \cdot \mathrm{s}$. The standard of SDG (purity $>98 \%$ by HPLC) was purchased from Shanghai Haling Biological Technology Co., Ltd. (Shanghai, China). HPLC-grade methanol was acquired from TEDIA Company (Fairfield, OH, USA). $\mathrm{K}_{2} \mathrm{HPO}_{4}, \mathrm{Na}_{2} \mathrm{SO}_{4}$, and $\left(\mathrm{NH}_{4}\right)_{2} \mathrm{SO}_{4}$ were of analytical grade and were purchased from Sinopharm Chemical Reagent Co., Ltd. (Shanghai, China). Other reagents were all analytical grade and used without treatment. Deionized water was used to prepare the sample solutions.

\subsection{Ionic Liquid-Based Ultrasound-Assisted Extraction}

The flaxseeds were smashed to powder of about 60 meshes $(250 \mu \mathrm{m})$ particle size. Then, $n$-hexane was added to the powder $(5: 1, v / m)$ and stirred for about $6 \mathrm{~h}$ for degreasing. After evaporating out the $n$-hexane and drying, degreased flaxseed powder was obtained. The IL aqueous solution was added to the degreased flaxseed powder for ultrasonic extraction of SDG in an ultrasonic bath (KQ-5200DE, Kunshan Ultrasound Co. Ltd., Kunshan, China).The electric power is $200 \mathrm{~W}$, generators frequency is $40 \mathrm{kHz}$, and operating temperature of $25{ }^{\circ} \mathrm{C}$ were set for this bath. The IL extract was centrifuged, and then hydrolyzed using $\mathrm{NaOH}$ aqueous solutions $(0.25-0.4 \mathrm{~mol} / \mathrm{L})$ for $2 \mathrm{~h}$. The $\mathrm{pH}$ value of the extract solution was adjusted to $4.0-6.0$ by $\mathrm{HCl}$ aqueous solution before analysis. Actually, SDG is a product of alkaline hydrolysis of polymeric lignans, the IL-UAE extract polymeric compounds without defined structure, which are subsequently hydrolyzed in presence of $\mathrm{NaOH}$. The latter gives a mixture of phenolic compounds, containing a certain amount of SDG. The SDG concentration was quantified using HPLC. The extraction yield of SDG by IL-UAE was calculated according to Equation (1):

$$
\text { Extraction yield }(\mathrm{mg} / \mathrm{g})=\frac{\text { Mass of } S D G \text { determined }(\mathrm{mg})}{\text { Mass of degreased flaxseed powder }(\mathrm{g})}
$$

\subsection{Ionic Liquids-Based Aqueous Two-Phase System}

SDG was extracted from the IL aqueous solution, and a certain amount of the IL-extract and a certain amount of salt were added to a tube. The tube was shaken well to completely dissolve the salt, and then it was centrifuged for complete phase formation. Two clear phases formed, and the volume of each phase was noted. SDG sample in IL-rich phase was withdrawn using a syringe, and then hydrolyzed using $\mathrm{NaOH}$ aqueous solutions $(0.25-0.4 \mathrm{~mol} / \mathrm{L})$ for $2 \mathrm{~h}$. The $\mathrm{pH}$ value of the sample was adjusted to $4.0-6.0 \mathrm{by} \mathrm{HCl}$ aqueous solution before HPLC analysis. The SDG concentration in the salt-rich phase was determined by mass balance. 
The phase ratio (R) was defined as in Equation (2):

$$
\mathrm{R}=\frac{\mathrm{V}_{\mathrm{t}}}{\mathrm{V}_{\mathrm{b}}}
$$

where $\mathrm{V}_{t}$ and $\mathrm{V}_{\mathrm{b}}$ are the volumes of IL-rich phase and salt-rich phase, respectively. The partition coefficient $(\mathrm{K})$ was defined as in Equation (3):

$$
\mathrm{K}=\frac{\mathrm{C}_{\mathrm{t}}}{\mathrm{C}_{\mathrm{b}}}
$$

where $C_{t}$ and $C_{b}$ are the SDG concentrations in the IL-rich phase and salt-rich phase, respectively. The extraction efficiency (E) of SDG in the IL-rich phase was determined from Equation (4):

$$
E=\frac{K}{\left(K+\frac{1}{R}\right)} \times 100 \%
$$

\subsection{HPLC Conditions}

SDG was quantified using Dionex UltiMate 3000 LC Modules (Sunnyvale, CA, USA), and equipped with an LPG-3400 pump (Sunnyvale, CA, USA) and a UV-Vis detector (model: VWD-3400, Sunnyvale, CA, USA). A personal computer equipped with Chameleon software was used to collect and process the chromatographic data. The analyses were performed with a Promosil C18 column $(250 \times 4.6 \mathrm{~mm}$ I.D.; $5 \mu \mathrm{m}$, Bonna-Agela Technologies, Tianjin, China). The mobile phase of SDG analysis was composed of methanol and $\mathrm{H}_{2} \mathrm{O}(33: 67 ; v / v)$ with isocratic elution. The flowrate was $1.0 \mathrm{~mL} / \mathrm{min}$, and the effluent was monitored at a wavelength of $290 \mathrm{~nm}$. The column temperature was maintained $30^{\circ} \mathrm{C}$. The samples were analyzed by injecting $20 \mu \mathrm{L}$ of the diluted sample into the HPLC. The mobile phase and samples before injection were filtered through a $0.45 \mu \mathrm{m}$ membrane. The linear regression equation is $Y=63.504 X+$ $0.5651\left(\mathrm{R}^{2}=0.9995\right)$, where $Y$ is the peak area and $X$ is the SDG concentration. Standard solutions of SDG were diluted at concentrations ranging from 0.25 to $4 \mathrm{mg} / \mathrm{mL}$.

\section{Conclusions}

An IL-UAE coupled with IL-ATPS methodology was developed for the extraction and purification of SDG from flaxseed. The IL $\left[\mathrm{C}_{4} \mathrm{mim}\right] \mathrm{N}(\mathrm{CN})_{2}$ was screened as the extractant due to its exceptional extraction ability. The optimized conditions determined using RSM for IL-UAE were IL concentration $55.49 \%(w / w)$, liquid-solid ratio 24.50:1, and ultrasonic irradiation time $40 \mathrm{~min}$. The maximum extraction efficiency (93.35\%) of SDG in the IL-rich phase resulted when the ATPS was composed of $45.86 \%(w / w)$ [C4mim] $\mathrm{N}(\mathrm{CN})_{2}$ and $8.27 \%(w / w) \mathrm{Na}_{2} \mathrm{SO}_{4}$ at $22{ }^{\circ} \mathrm{C}$ and $\mathrm{pH} 11.0$. This combination of IL-UAE and IL-ATPS provides a simple, efficient, and environmentally friendly methodology for the extraction and purification of SDG from flaxseeds. This process is also expected to be useful for the extraction of other bioactive compounds. 


\section{Acknowledgments}

This work was financially supported by the National Natural Science Foundation of China (No. 21406262) and the Agricultural Science and Technology Innovation Program (No. ASTIP-IBFC07).

\section{Author Contributions}

Z.-J.T. and C.-Y.W. designed overall research experiments; Z.-Z.Y., W.-L.Z., Y.-J.Y. and H.-Y.W. performed the experiments; Z.-J.T. wrote and revised the manuscript; and F.-F.L. revised the manuscript.

\section{Conflicts of Interest}

The authors declare no conflict of interest.

\section{References}

1. Peterson, J.; Dwyer, J.; Adlercreutz, H.; Scalbert, A.; Jacques, P.; McCullough, M.L. Dietary lignans: Physiology and potential for cardiovascular disease risk reduction. Nutr. Rev. 2010, 68, 571-603.

2. Nemes, S.M.; Orsat, V.; Raghavan, G.V. Calibration of artificial neural network and partial least squares regression models for the prediction of secoisolariciresinol diglucoside contents in microwave-assisted extracts of various flaxseed (Linum usitatissimum L.) samples. Food Chem. 2012, 133, 1588-1595.

3. Hano, C.; Renouard, S.; Molinie, R.; Corbin, C.; Barakzoy, E.; Doussot, J.; Lamblin, F.; Laine, E. Flaxseed (Linum usitatissimum L.) extract as well as $(+)$-secoisolariciresinol diglucoside and its mammalian derivatives are potent inhibitors of $\alpha$-amylase activity. Bioorg. Med. Chem. Lett. 2013, 23, 3007-3012.

4. Fuentealba, C.; Figuerola, F.; Estévez, A.M.; González-Muñoz, A.; Muñoz, O. Optimization of secoisolariciresinol diglucoside extraction from flaxseed (Linum usitatissimum L.) and isolation by a simple HPLC-UV method. CyTA-J. Food 2015, 13, 273-281.

5. Rizwan, S.; Naqshbandi, A.; Farooqui, Z.; Khan, A.A.; Khan, F. Protective effect of dietary flaxseed oil on arsenic-induced nephrotoxicity and oxidative damage in rat kidney. Food Chem. Toxicol. 2014, $68,99-107$.

6. Goyal, A.; Sharma, V.; Upadhyay, N.; Gill, S.; Sihag, M. Flax and flaxseed oil: An ancient medicine \& modern functional food. J. Food Sci. Technol. 2014, 51, 1633-1653.

7. Oomah, B.D. Flaxseed as a functional food source. J. Sci. Food Agric. 2001, 81, 889-894.

8. Moree, S.S.; Kavishankar, G.B.; Rajesha, J. Antidiabetic effect of secoisolariciresinol diglucoside in streptozotocin-induced diabetic rats. Phytomedicine 2013, 20, 237-245.

9. Hu, C.; Yuan, Y.V.; Kitts, D.D. Antioxidant activities of the flaxseed lignan secoisolariciresinol diglucoside, its aglycone secoisolariciresinol and the mammalian lignans enterodiol and enterolactone in vitro. Food Chem. Toxicol. 2007, 45, 2219-2227.

10. Ayella, A.; Lim, S.; Jiang, Y.; Iwamoto, T.; Lin, D.; Tomich, J.; Wang, W. Cytostatic inhibition of cancer cell growth by lignan secoisolariciresinol diglucoside. Nutr. Res. 2010, 30, 762-769. 
11. Chen, J.; Saggar, J.K.; Corey, P.; Thompson, L.U. Flaxseed and pure secoisolariciresinol diglucoside, but not flaxseed hull, reduce human breast tumor growth (MCF-7) in athymic mice. J. Nutr. 2009, 139, 2061-2066.

12. Prasad, K. Hypocholesterolemic and antiatherosclerotic effect of flax lignan complex isolated from flaxseed. Atherosclerosis 2005, 179, 269-275.

13. Rogers, R.D.; Seddon, K.R. Ionic liquids - Solvents of the future? Science 2003, 302, 792-793.

14. Rogers, R.D. Materials science-Reflections on ionic liquids. Nature 2007, 447, 917-918.

15. Neves, C.M.; Ventura, S.P.; Freire, M.G.; Marrucho, I.M.; Coutinho, J.A. Evaluation of cation influence on the formation and extraction capability of ionic-liquid-based aqueous biphasic systems. J. Phys. Chem. B 2009, 113, 5194-5199.

16. Tang, S.; Baker, G.A.; Zhao, H. Ether- and alcohol-functionalized task-specific ionic liquids: Attractive properties and applications. Chem. Soc. Rev. 2012, 41, 4030-4066.

17. Zhang, Y.; Liu, Z.; Li, Y.; Chi, R. Optimization of ionic liquid-based microwave-assisted extraction of isoflavones from Radix puerariae by response surface methodology. Sep. Purif. Technol. 2014, $135,285-285$.

18. Ge, L.; Xia, F.; Song, Y.; Yang, K.; Qin, Z.; Li, L. Solubility of luteolin in several imidazole-based ionic liquids and extraction from peanut shells using selected ionic liquid as solvent. Sep. Purif. Technol. 2014, 135, 223-228.

19. Ribeiro, B.D.; Coelho, M.A.Z.; Rebelo, L.P.N.; Marrucho, I.M. Ionic liquids as additives for extraction of saponins and polyphenols from mate (Ilex paraguariensis) and tea (Camellia sinensis). Ind. Eng. Chem. Res. 2013, 52, 12146-12153.

20. Ribeiro, B.D.; Coelho, M.A.Z.; Marrucho, I.M. Extraction of saponins from sisal (Agave sisalana) and juá (Ziziphus joazeiro) with cholinium-based ionic liquids and deep eutectic solvents. Eur. Food Res. Technol. 2013, 237, 965-975.

21. Tang, B.; Lee, Y.J.; Lee, Y.R.; Row, K.H. Examination of 1-methylimidazole series ionic liquids in the extraction of flavonoids from Chamaecyparis obtuse leaves using a response surface methodology. J. Chromatogr. B 2013, 933, 8-14.

22. Xiao, Y.; Wang, Y.; Gao, S.; Zhang, R.; Ren, R.; Li, N.; Zhang, H. Determination of the active constituents in Arnebia euchroma (Royle) Johnst. by ionic liquid-based ultrasonic-assisted extraction high-performance liquid chromatography. J. Chromatogr. B 2011, 879, 1833-1838.

23. Chatel, G.; Macfarlane, D.R. Ionic liquids and ultrasound in combination: Synergies and challenges. Chem. Soc. Rev.2014, 43, 8132-8149.

24. Harde, S.M.; Lonkar, S.L.; Degani, M.S.; Singhal, R.S. Ionic liquid based ultrasonic-assisted extraction of forskolin from Coleus forskohlii roots. Ind. Crop. Prod. 2014, 61, 258-264.

25. Yang, L.; Li, L.L.; Liu, T.T.; Zu, Y.G.; Yang, F.J.; Zhao, C.J.; Zhang, L.; Chen, X.Q.; Zhang, Z.H. Development of sample preparation method for isoliquiritigenin, liquiritin, and glycyrrhizic acid analysis in licorice by ionic liquids-ultrasound based extraction and high-performance liquid chromatography detection. Food Chem. 2013, 138, 173-179.

26. Wang, W.C.; Li, Q.Y.; Liu, Y.H.; Chen, B.B. Ionic liquid-aqueous solution ultrasonic-assisted extraction of three kinds of alkaloids from Phellodendron amurense Rupr and optimize conditions use response surface. Ultrason. Sonochem. 2015, 24, 13-18. 
27. Gutowski, K.E.; Broker, G.A.; Willauer, H.D.; Huddleston, J.G.; Swatloski, R.P.; Holbrey, J.D.; Rogers, R.D. Controlling the aqueous miscibility of ionic liquids: Aqueous biphasic systems of water-miscible ionic liquids and water-structuring salts for recycle, metathesis, and separations. J. Am. Chem. Soc. 2003, 125, 6632-6633.

28. Han, J.; Wang, Y.; Liu, Y.; Li, Y.; Lu, Y.; Yan, Y.; Ni, L. Ionic liquid-salt aqueous two-phase extraction based on salting-out coupled with high-performance liquid chromatography for the determination of sulfonamides in water and food. Anal. Bioanal. Chem. 2013, 405, 1245-1255.

29. Passos, H.; Trindade, M.P.; Vaz, T.S.; da Costa, L.P.; Freire, M.G.; Coutinho, J.A.P. The impact of self-aggregation on the extraction of biomolecules in ionic-liquid-based aqueous two-phase systems. Sep. Purif. Technol. 2013, 108, 174-180.

30. Sha, O.; Zhu, X.S.; Feng, Y.L.; Ma, W.X. Aqueous two-phase based on ionic liquid liquid-liquid microextraction for simultaneous determination of five synthetic food colourants in different food samples by high-performance liquid chromatography. Food Chem. 2015, 174, 380-386.

31. Tan, Z.J.; Li, F.F.; Xu, X.L.; Xing, J.M. Simultaneous extraction and purification of aloe polysaccharides and proteins using ionic liquid based aqueous two-phase system coupled with dialysis membrane. Desalination 2012, 286, 389-393.

32. Claudio, A.F.; Ferreira, A.M.; Freire, C.S.; Silvestre, A.J.; Freire, M.G.; Coutinho, J.A. Optimization of the gallic acid extraction using ionic-liquid-based aqueous two-phase systems. Sep. Purif. Technol. 2012, 97, 142-149.

33. Abdolrahimi, S.; Nasernejad, B.; Pazuki, G. Influence of process variables on extraction of cefalexin in a novel biocompatible ionic liquid based-aqueous two phase system. Phys. Chem. Chem. Phys. 2015, 17, 655-669.

34. Jiang, B.; Feng, Z.; Liu, C.; Xu, Y.; Li, D.; Ji, G. Extraction and purification of wheat-esterase using aqueous two-phase systems of ionic liquid and salt. J. Food Sci. Technol. 2015, 52, 2878-2885.

35. Jacquemin, J.; Husson, P.; Padua, A.A.; Majer, V. Density and viscosity of several pure and water-saturated ionic liquids. Green Chem. 2006, 8, 172-180.

36. Bogdanov, M.G.; Svinyarov, I. Ionic liquid-supported solid-liquid extraction of bioactive alkaloids. II. Kinetics, modeling and mechanism of glaucine extraction from Glaucium flavum Cr. (Papaveraceae). Sep. Purif. Technol. 2013, 103, 279-288.

37. Sun, Y.; Liu, Z.; Wang, J.; Yang, S.; Li, B.; Xu, N. Aqueous ionic liquid based ultrasonic assisted extraction of four acetophenones from the Chinese medicinal plant Cynanchum bungei Decne. Ultrason. Sonochem. 2013, 20, 180-186.

38. Bogdanov, M.G. Ionic liquids as alternative solvents for extraction of natural products. In Alternative Solvents for Natural Products Extraction; Chemat, F., Abert-Vian, M., Eds.; Springer: Berlin/Heidelberg, Germany, 2014; pp. 127-166.

39. Yang, L.; Ge, H.; Wang, W.; Zu, Y.; Yang, F.; Zhao, C.; Zhang, L.; Zhang, Y. Development of sample preparation method for eleutheroside $\mathrm{b}$ and e analysis in Acanthopanax senticosus by ionic liquids-ultrasound based extraction and high-performance liquid chromatography detection. Food Chem. 2013, 141, 2426-2433. 
40. Bogdanov, M.G.; Keremedchieva, R.; Svinyarov, I. Ionic liquid-supported solid-liquid extraction of bioactive alkaloids. III. Ionic liquid regeneration and glaucine recovery from ionic liquid-aqueous crude extract of Glaucium flavum Cr. (Papaveraceae). Sep. Purif. Technol. 2015, doi:10.1016/j.seppur. 2015.02.003.

Sample Availability: Samples of the compounds flaxseed powder are available from the authors.

(C) 2015 by the authors; licensee MDPI, Basel, Switzerland. This article is an open access article distributed under the terms and conditions of the Creative Commons Attribution license (http://creativecommons.org/licenses/by/4.0/). 